\title{
In memoriam Prof. David Zeitoun (1945-2021)
}

\author{
Y. Burtschell ${ }^{1} \cdot$ A. Zeitoun ${ }^{1}$
}

(c) Springer-Verlag GmbH Germany, part of Springer Nature 2021

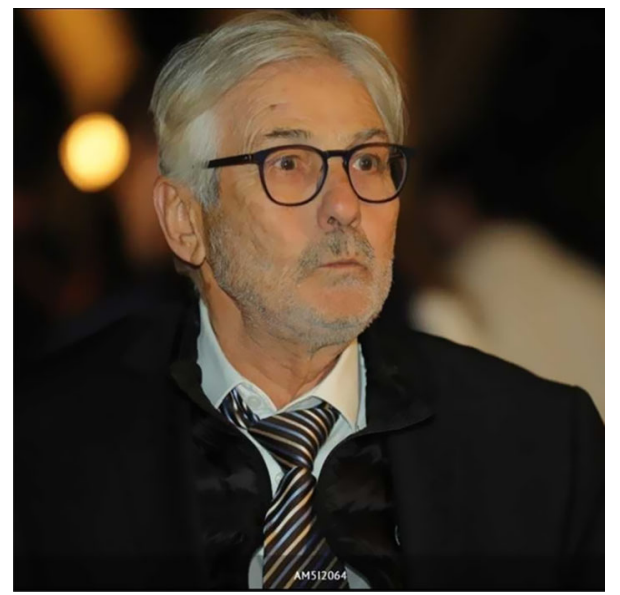

Prof. David Zeitoun was born in Tunisia on March 19, 1945, near Tunis in the district of La Goulette. He arrived in France in his teens and settled with his parents in the south of France in Marseille. Curious by nature, David Zeitoun naturally turned to scientific studies and more particularly to fluid mechanics, the subject of his graduate thesis which he defended in December 1970.

David Zeitoun joined the University of Provence in Marseille in 1972 as a research engineer. He defended his $\mathrm{PhD}$ thesis in 1978 in the Milieux Hors Equilibre (MHEq) team directed by Prof. Raymond Brun at the SETT laboratory (now IUSTI) in Marseille. There he developed an aspect of fluid mechanics that was relatively new for the team at that time: numerical simulations. He wrote one of the laboratory's first computational codes on punched cards!

In 1981, he became interested in the calculation of a thermal boundary layer behind a shock wave reflected at the end of a shock tube. Then by applying the finite difference method, he determined the different states of stationary flows in thermochemical nonequilibrium, also encountered in other configurations such as laser or expansion nozzles.

Y. Burtschell

yves.burtschell@univ-amu.fr

1 POLYTECH Marseille, Aix-Marseille Université - Campus Etoile, JOLIOT CURIE, 60 rue F. Joliot-Curie,

13453 Marseille, France
In 1988, he was promoted to the rank of Full Professor. He actively participated, within the framework of the European space shuttle project HERMES, in the study of a free-piston shock tunnel generating hypersonic flows up to Mach 6. The construction of this wind tunnel, called TCM2, was completed in 1991 at the IUSTI laboratory (former SETT) in Marseille.

At the same time, he contributed with other members of the MHEq team to the development of physico-chemical models (CVD-CVDV-CVDEV) that he applied numerically to the flows encountered in the expansion nozzle of TCM2 and around different blunt bodies. He also encouraged the development of an unsteady approach in numerical simulations, by using a finite-volume approach for the prediction of flows in TCM2. For example, the pollution of the hot gas by the driver gas through the boundary layer at the bottom of a shock tube was numerically highlighted.

In the 2000s, he studied hysteresis phenomena in stationary shock reflections (RR, MR, DMR, VMI) in collaboration with several researchers, such as Prof. Gabi Ben-Dor, Prof. Amer Chpoun, and Prof. Michael Ivanov.

Between 2005 and 2009, he took part in the European research program EUROCHINA 1 and 2, promoting thereby scientific cooperation between Europe and China in the field of multiphysics modeling, simulation, experimentation, and design methods in aeronautics.

As a teacher and researcher, David Zeitoun organized several conferences and workshops during his career, particularly he chaired and organized with Prof. Raymond Brun the 19th ISSW held in Marseille in 1993. He has also fulfilled pedagogical, elective, and administrative functions. In 2004, he was appointed Director of the Mechanical-Energy Department of Polytech Marseille and then became Director of this Engineering School until 2012.

At retirement age, David Zeitoun was appointed Professor Emeritus at Aix Marseille University. He continued his research activities, by deepening, among others, the numerical study of shock waves in micro-channels initiated in 2006.

$\mathrm{He}$ is the author of approximately 150 international publications and communications and has supervised approxi- 
mately $25 \mathrm{PhD}$ theses and HDRs. He was a member of the ISSW International Advisory Committee and the Editorial Board of the International Journal Shock Waves.

Very discreet about his private life, he was married and the father of two children. But above all, he was a grandfather who was very present for his grandchildren, very motivated and motivating in the follow-up of their sport activities and their scientific studies. His ambition has always been to share his knowledge with them.
David Zeitoun passed away on March 2, 2021 at the age of 75 .

Publisher's Note Springer Nature remains neutral with regard to jurisdictional claims in published maps and institutional affiliations. 